\title{
Knowing Well-being: A History of Data
}

\subsection{What Is WeLL-Being?}

Centuries of philosophical inquiry have failed to result in agreement about what the 'good life' is. (Veenhoven 1984, 18)

How do we know what well-being is? The term 'well-being' is familiar and widespread and yet there is ambiguity around its definition. There are even disagreements in whether it is spelt 'well-being' or wellbeing. 'Health and well-being' or 'mental health and well-being' are common expressions in public services and formal reports, from housing to arts councils (i.e. ACE 2018). While well-being is key to social policy-making (Wolf 2019), it is increasingly distinguished from 'welfare' (Scott 2012, 37) and instead linked to what we now call 'the wellness industry', which, at its extreme is seen as a hybrid of clean eating, yoga and meditation (Cederström and Spicer 2014; Davies 2015). So, well-being can therefore be used to describe health, but more than health; it is key to public services, but is not used to describe welfare, as such-and the very idea of well-being has been co-opted by big business who want to sell us what they want us to believe is good for us.

This chapter asks the question: 'knowing well-being, how did we get here?' Its main aim is to present the historical and policy context of wellbeing as an agenda. 'The well-being agenda' has emerged as a consequence of people and organisations considering it a priority: as a problem that

(C) The Author(s) 2021

S. Oman, Understanding Well-being Data, New Directions in Cultural Policy Research, https://doi.org/10.1007/978-3-030-72937-0_2 
needs solving, or an aim that warrants achieving. You might be familiar with the idea of a policy agenda: the well-being agenda is bigger than policy, with more individuals and associations involved and with an interest. We will establish how well-being is used, including definitions and traditions of well-being, beginning to see how well-being data ${ }^{1}$ emerge as useful for measurement, and how measurement is used to know about well-being in certain ways. Well-being measures have two main uses: to track the health and wealth of nations and to make policy decisions. These involve either evaluating previous interventions or predicting how a future decision might have positive impact. The chapter reflects on well-being as a tool of policy that emerged as a result of an agenda across academic, technical, commercial and political interests. The story of the well-being agenda is important to understanding contemporary society, and the role of data, vital to it.

Some see well-being as synonymous with happiness, ${ }^{2}$ and therefore arguably only a part of the human experience, and others as an allencompassing concept to describe the quality of people's lives (Dodge et al. 2012). We will explore these aspects in Chaps. 3 and 4. As Veenhoven (1984) suggests, well-being as a concept can also encompass broader ideas about what a good life might be; which others, such as the Greek philosopher Aristotle saw as connected to how we might envisage a good society (Aristotle 1976). ${ }^{3}$ It can therefore describe how humans experience the world as individuals, or as society.

Well-being is also used to describe things which aren't really about people or life at all, such as 'the well-being of the sector' when talking about the arts and culture (UK Parliament 2018) and 'the well-being of the economy'. We have seen this used recently to justify releasing of lockdown laws which were in place to protect the vulnerable, following peaks of coronavirus infections in the UK (John 2020). This linguistic trick can lead someone to connect the economy to well-being, when they would not necessarily have done before.

The well-being of the economy is not 'well-being economics', however, which aims to re-focus away from economic policy to account for the negative effects of growth on people and the planet. Think of the links between McDonald's and the destruction of the Amazon rainforest, for example (Vidal 2006), and calls for a 'local economy'. Thus, well-being economics is often ideologically opposite to concerns that we must safeguard the economy, instead directing attention to protecting community infrastructures and interests, while being sensitive to impacts on the planet in a move 'towards sustainability' (see Scott 2012). 


\section{Box 2.1 Ideology}

When this book talks about ideology, it means a set of ideas that go together, as is common in a political ideology, like socialism, fascism or democracy, for example. The well-being of the economy might be thought to ideologically put the economy first, whereas well-being economics wants to foreground protecting people and the planet over economic growth.

Some economists and psychologists, however, might refer to 'happiness economics' when thinking about well-being. Rooted in positive psychology and behavioural psychology, happiness economics is based on the premise that what we do affects our well-being, and that people can make better decisions for themselves (Dolan 2014; Layard 2006). The approach has been adopted in policy-making as it offers rationales for decisionmaking and has also been capitalised on. For example, the digital mental health market was valued at $\$ 1.4$ billion ( $£ 1.1$ billion) in 2017 and is projected to reach $\$ 4.6$ billion in 2026 (Morris 2020). This industry commercialises a solution for people's desire to improve themselves or make themselves feel better. If you take a moment to think about how making people feel more responsible for their own well-being is attractive to those in government who want to be less accountable for our well-being, this may make you feel suspicious of the links across the business of well-being and the governance of our welfare.

The well-being agenda has, therefore, manifested in different camps with different agendas - which have different relationships with data. As a result, we have different kinds of well-being data that are produced and generated for different purposes. They are also used differently: various parts of society use well-being data to manage themselves - and othersin different ways. ${ }^{4}$ This makes it difficult to navigate well-being data and how it is used, or how we should use it-both in our own work, and when reading about others' work in our everyday lives or when watching the news.

While this book's primary concern is not to define well-being, nor is it to re-document the histories of ideas around well-being (there are many other excellent books which have done these things e.g. Davies 2015; Layard 2006; McMahon 2006; Schoch 2007), the fact that there is no single use of the term makes it complicated. It is also what makes it so 
valuable for those who use well-being data to suit their aims, needs and communicate their beliefs.

This book is designed to help navigate the complexities of well-being data: to reveal the roots of the well-being data you encounter professionally or in everyday life. So, in order to do that let's first outline how different aspects of well-being have been imagined historically, how they have been defined. We will also need to account for different moments in time that have resulted in the varieties and uses of well-being data. These political histories contextualise why certain data are generated, how they are generated-and how they may not represent what you may imagine. With this background knowledge and understanding, you should find it easier to navigate 'well-being' as an intellectual field; a social, cultural and personal aspiration; and a policy agenda. This helps understand different forms of well-being data-and how they are used.

\section{Traditions of Well-being Thought}

There are two overarching ideas of well-being which emerge from two main traditions. These are found in the way well-being data are most often used to inform policy-making or evaluate decisions made in organisations. These two traditions have been described as 'Benthamite-subjectivehedonic-individualistic' or 'Aristotelian-objective-eudaimonic-rational' (Bruni and Porta 2005, 20). This way of describing these two traditions is a bit of a mouthful and can be broken down.

\section{Hedonia: Most Simply Understood as Pleasure or Positive Feeling}

The first account of well-being is based on hedonia: most simply understood as pleasure. The easiest way to remember its meaning is through the words: hedonism and hedonistic, as meaning 'a bit of a party animal' or as a good friend used to say: 'a pleasure monster'. This is a recent adaptation, however. Historically, it was grounded in peoples' subjective experience of their own lives. Hedonia is philosophically rooted in the Epicureans' (c. $300 \mathrm{BC}$ ) belief that pleasure is good-and morally virtuous to aspire towards. This was later adapted by the Utilitarians: Bentham asserted that an act was good based upon the outcome of the act, specifically, if it provided more happiness for more people than harm. As a result, he believed that the maximisation of pleasure, and reduction of suffering, was the role of government (1996 [1789]). 
Jeremy Bentham's 'hedonic calculus', also known as the 'felicific calculus', was a theoretical algorithm. We tend to think of algorithms as a recent invention, but instead it is a term from the late seventeenth century referring to a series of rules for problem solving, particularly in calculations. ${ }^{5}$ Bentham proposed to understand the moral worth of an act as its value. By which he meant, that he wanted to be able to come up with a valuation mechanism to understand how people's actions were moral, based on their contribution to happiness. The economist Francis Edgeworth, some 100 years later, argued that utility was directly measurable. Utility is a term in economics that does not refer to the cost of your water bill, but instead captures the idea that when people consume a good or service, they do so to gain satisfaction. We will come to this in greater detail later, but much economics works on the proviso that humans make rational choices that will maximise the utility and the experience. Edgeworth believed that new developments in 'physio-psychology' made a 'hedonimeter' possible. The hedonimeter was imagined to measure pleasure through reading bodily responses. This, he argued, would allow economists a physiological underpinning of utility, based on the natural sciences (Colander 2007). In other words, it would prove the existence of rational choice and satisfaction, rather than this only being a theory. Improving knowledge of how we experience the world: our pleasure and pain is one of the motivations behind wanting to understand well-being. Making this seem more scientific is one of the drivers behind measuring it and using data, as is the idea of living a good life.

\section{Eudaimonia: Most Often Understood as Purpose or Flourishing}

The second account is not based on a mental state, as such, but on the process involved in human flourishing, as living our best possible life. This Aristotelian account of well-being, eudaimonia, is formed by what we do across all the aspects of our lives and is more aligned to purpose, rather than pleasure (Aristotle c. 330 BC). These days, many worry that Aristotle's ideas of living a best life (1976) go too far: they are too idealistic and purist. In order to live a good life, a person had to separate themselves from the mundane to consider the theoretical and the scientific. This not only is exclusionary, by today's standards, but depends on others to undertake these mundane activities. Despite the societal issues of slavery and elitism of Aristotle's Athens, ${ }^{6}$ much of his thinking of Eudaimonia remains in use.

The binary of pleasure versus purpose grounds much of the well-being discourse. It manifests in proposals of how to achieve both in self-help literature (e.g. see Dolan 2014), or the role of government in reducing 
suffering or maximising people's opportunities to flourish (Sen 1999). The two traditions have been described as 'Benthamite-subjectivehedonic-individualistic' and 'Aristotelian-objective-eudaimonic-rational' (Bruni and Porta 2005, 20). As we have briefly covered these concepts separately, with any luck, they now mean more than a string of words. I'll now break down the last of those differences (individual vs rational), although, as will become clear later, the positions are not as much in opposition to each other as implied.

Individualism, as you might expect, foregrounds the individual. This position sees the moral right to autonomy, and the importance that people make their own decisions. It involves understanding how individual people live and appreciate things differently, which is why it has been aligned with the subjective and centres on experience. However, this should not necessarily mean that people can only care for themselves. Bentham, for example, believed the role of government was to enable the most happiness for the largest number of people ${ }^{7}$ (Bentham (1996 [1789])).

Rationalism, on the other hand, does not necessarily seek empirical truth of experience, by which we mean concrete evidence of what someone else is feeling. Instead it favours what can be deduced via logical intellectual engagement. Rationalist thinking therefore seeks objective ways of understanding the world: meaning those who aspire to rationalism, also aspire towards facts which can be neutrally observed. In other words, how they feel or what they expect should not affect judgement. It is, as we shall discover, more difficult to be a neutral thinker, than you may imagine; similarly, the methods and tools used to capture objective data are not able to capture 'raw data', ${ }^{8}$ but all data are contextual and shaped by decisions made on how they are collected and interpreted.

In general, the data that comprise objective indicators are considered more reliable than those in subjective indicators. If we think on a smaller, more everyday scale: in healthcare, objective data include X-rays, and subjective data include the reporting of symptoms. If you were to make a diagnosis of a broken rib, you would use a combination of these data, but the X-rays would be considered more reliable than someone saying they feel like they have broken a rib. However, if someone said they felt as if they'd broken a rib, and the X-ray said otherwise, you would undertake another test to collect more objective data. Statistics doesn't quite work like that as you very rarely go to the individual level to see how one bit of objective data corresponds to a subjective one. This, however, might be tested using qualitative research like interviews, which we'll discuss in the 
next chapter. Having briefly summarised the theoretical background to ideas of well-being and their uses, we will begin to look more at data and how they can be used by the well-being agenda.

\section{Common Definitions Used with Well-being Data}

There is no single definition of wellbeing. The terms wellbeing, quality of life, happiness, life satisfaction and welfare are often used interchangeably (although some disciplines draw distinctions between them). (Allin 2007,46)

Paul Allin became Director of the UK's Office for National Statistics' (ONS') Measuring National Well-being programme. As he acknowledges above, there are a number of terms used as if they are substitutable in disciplines associated with measuring well-being. In addition to happiness, life satisfaction and quality of life are also synonymous with well-being. As we shall find out throughout the book, when it comes to data, although these ideas are linked in a common-sense way, life satisfaction metrics are largely from different sorts of data than quality-of-life metrics. Life satisfaction measures aim to capture how people feel and so they are from subjective evaluations. Quality-of-life measures are used to understand various qualities of life, such as health and relationships; the endgame is understanding how these work together, to then assess overall well-being. They are made from objective lists and measures.

\section{Objective Well-being}

This approach examines what are thought to be the components of the good life, using objective data which include resources (income, food, housing) and social attributes (education and health). Objective wellbeing data are then added up (aggregated) to become society-wide descriptions that imply concrete conditions, such as employment rate or life expectancy. They are objective because they measure material conditions, and are considered impartial. They are well-being data as they are used to understand how something like housing or income might impact our lives. In other words, they can be used as a proxy measure for wellbeing. By proxy we mean an indirect measure. For example, someone's income does not necessarily directly tell you about their quality of life, but because the relationship has been long-studied, assumptions can be made about well-being using what we know about how income relates to wellbeing - so the theory goes. 
Objective well-being data predominantly come from what we call administrative data. These data are collected in the processes of our everyday lives, like taxation or the registration of births, marriages and deaths. Objective data are also collected from people using surveys. Questions that ask for details on salary and how many people live in someone's home (like in the census), for example, are objective. Chapter 3 looks at objective lists and measures in much greater detail.

\section{Subjective Well-being}

As with health diagnoses, subjective well-being data are generated by asking people questions about how they are doing and/or how they are feeling. This can be about their material conditions: how they feel about their local area; is it clean; is it safe? It can also be how they are feeling in and of themselves. One example is the UK's ONS' four questions to understand personal well-being. We will return to 'the ONS4' often in this book. They ask:

1. Overall, how happy did you feel yesterday?

2. Overall, how satisfied are you with your life nowadays?

3. Overall, to what extent do you feel the things you do in your life are worthwhile?

4. Overall, how anxious did you feel yesterday?

People score themselves out of ten, with most scoring around a seven out of ten for life satisfaction. These scores are aggregated to become the well-being data of a population who answered these questions. These aggregated data are used in a number of ways which can be tracked over time. Subjective measures are also used against objective measures, so if a measure of poverty spikes, we can see if this appears to be linked to anxiety using data produced by question 3. More recently, subjective well-being questions have been used to track impacts of the COVID-19 pandemic on different samples of different populations all across the world.

As we have touched on, understanding the human experience in a more scientific way is one of the key drivers of the well-being agenda. Chapter 4 looks in greater detail at the study of subjective well-being as 'a new science' (Layard 2006). Interestingly, this 'new science of happiness' is one of the academic and intellectual developments that saw a resurgence in interest in well-being measurement more generally, especially in policy. Somewhat confusingly, the well-being agenda-as the measurement of 
well-being-tends to be discussed in terms of objective indicators to replace Gross Domestic Product (GDP), rather than subjective well-being. As we discover in the next section, this is a more complex history than is ordinarily accounted for.

\subsection{Measuring Well-being to Improve Human Welfare: A Brief History}

The measurement of well-being and quality of life for policy-making has recently been described as 'an idea whose time has come' (Bache and Reardon 2013). Articles on happiness and well-being averaged less than five a year in the journals covered by the EconLit database ${ }^{9}$ in the 1990s. By 2008 this had risen to over 50 each year (Fleche et al. 2012, 8). Bache and Reardon (2013) historicise this surge in interest as a political phenomenon that they term 'the second wave of well-being'.

The first wave of well-being evolved as a project of redistribution after World War II. Prior to this, in the 1920s, Gross Domestic Product was developed as a broad quantitative measure of a nation's total economic activity. It was treated as a proxy for increases in individual wealth, and fluctuations in unemployment, thereby tracking material quality of life at national level. A recent history of national accounts in different countries indicates that the well-being of citizens, not their bank accounts, was considered to be the end goal of government (Perlman and Marietta 2005). The goal of collecting information on income distribution, growth and productivity was to examine how those indicators influence the welfare of the nation, according to economist Simon Kuznets, one of the originators of GDP. Although Kuznets also acknowledged that economic indicators were only one piece of the puzzle of citizens' well-being, and that 'the welfare of a nation can 'scarcely be inferred from a measurement of national income' (Kuznets 1934, report to congress, cited in OECD 2007). He was, therefore, arguing for the value of GDP as an instrument, but aware of its limitations, crucially stating:

Goals for more growth should specify more growth of what and for what. (Kuznets in Croly 1962)

GDP and national accounts data were not only generated to go about understanding individual nations, but also meant that countries could be compared in these terms, reflecting a broader trend towards comparable 
data across nations at this time. In 1924, the League of Nations Health Organisation created the Permanent Commission on Biological Standardisation to monitor drug tests. This increasing momentum to share information on populations, including unemployment, wages and migration led to the new International Statistical Commission in 1947. The modern term 'statistics' was, in fact, coined with the invention of new system of accounting for national governance to ascertain 'the quantum of happiness' with a view to using these data to govern the nation better (Sinclair 1798, vol. 20, xiii).

Growing concerns evolved in the 1950s that personal prosperity created social costs which manifested as public poverty ${ }^{10}$ (Noll 2002). There was also growing recognition that these social costs could not be captured by GDP. It was decided that this needed to be addressed through the development of new measurement tools that could help track whether life was actually getting better. These were hoped to be able to compensate for some of the shortcomings of GDP as a measure of human progress.

This is what came to be known as 'the social indicators movement', which emerged in the spirit of redistribution and an aspiration for new levels of knowledge of everyday life, birthing new surveys, such as the Level of Living Survey (The Swedish Institute for Social Research 1968; ONS 1970). These alternative but 'objective' benchmarks of progress grew in relevance on the international political agenda (Scott 2012; McGillvray 2007 in Bache 2012). The economic collapse of the 1970s is believed to have compromised the impact of these new indicators. The fact that economics had failed to avert economic crisis (Bache 2012), alongside a growing distrust of government, prevented the social indicator movement from toppling GDP as the primary measure of prosperity, and thus the focus on progress as growth remained.

The 'second wave' of well-being began in the comparative prosperity of the late 1990s (Bache and Reardon 2013) and was cemented in the highprofile commission of leading international economists. ${ }^{11}$ This responded to ongoing work of the OECD and concerns that material growth was impacting negatively on the planet (Bache 2012). It also responded to what has become known as the Easterlin paradox (1973): the discovery that rising wealth was not-in fact-improving people's life satisfaction. The commission recommended, with considerable influence, that an alternative benchmark of progress should be found that was able to measure more than GDP and that all nations find a way to measure their own wellbeing. This task was taken on by most OECD countries, in different ways, 
and its timing in the UK resulted in its branding as Conservative Prime Minister of the Coalition Government, 'Cameron's happiness index', when it was a far bigger movement that started a decade earlier.

The second wave also coincided with recent developments in subjective well-being data collection. The ONS example which they called Personal Well-being was introduced in April 2011. ${ }^{12}$ The measurement of subjective well-being for policy emerges from 'happiness economics' (Layard 2006), which builds on work in the positive psychology movement (e.g. Seligman and Csikszentmihalyi 2000) and which we explore in Chap. 4. Richard Layard (2006) used the term 'hedonic treadmill'13 in response to the Easterlin paradox. It describes how we adapt to increasing wealth, resulting in a need for more income to maintain the levels of life satisfaction we are accustomed to. This results in greater consumption, which causes material growth and negative planetary impacts. Around the same time, other research was beginning to note the positive impacts of more social aspects of life on subjective well-being: social interaction, faith, intimate relationships, government spending and different politicalinstitutional frameworks (Bache and Reardon 2013).

The demise of the social indicators movement in the 1970s was arguably not only the result of economic downturn (Scott 2012). Instead weaknesses in the objective indicators and data themselves made them unsustainable. Described as a 'bewildering array', these metrics were not linked to a robust theoretical or ideological analysis of what quality of life was exactly. The metrics and their analysis did not answer what needed to be achieved for whom and how (Scott 2012, 36). Thus, the second wave appealed to these proclaimed deficiencies.

The history of well-being measurement raises important questions regarding what measures are suitable for policy. Experts argue that the science behind measuring well-being is becoming more robust (O'Donnell et al. 2014; Helliwell et al. 2015; Cameron 2010; ONS 2015), but do the indices address the fundamental question of what 'quality of life' $i s$ ? Do they accommodate how people will find different qualities more valuable in various circumstances? Also, if wealth remains a proxy for well-being for some, and addressing well-being inequality ${ }^{14}$ is a new policy focus, has it been decided how redistribution of well-being would be undertaken in practice?

The very essence of well-being, as it is generally understood (particularly subjective well-being), not only is attached to the lived experience, but should encompass it. Instead, well-being is often discussed in a 
detached way as an object of politics that changes over time. Some argue that this is as a consequence of it becoming measurable (Beer 2016; Davies 2015; Doria 2013; White 2014) which means well-being assumed its own agency, and in ways which are not necessarily understood by the general public. Others argue that this is the very consequence of attributing value to values (Doria 2013; Kaszynska 2021). This obscures the political motivations, and the power of those creating and operationalising the measures and models, for policy evaluation. Remember when we were thinking about the idea of facts being neutrally observed, as objective and neutral, without factors which can affect judgement? Power is one reason why neutrality is harder to prove or argue than is always recognised.

These are the politics of data. It is imperative to consider these issues if we are to respond to the well-being agenda, including calls to move from 'national well-being measurement to a national well-being strategy' in a report by the All-Party Parliamentary Group (APPG) on Wellbeing Economics (Berry 2014, 4). Furthermore, different policy domains take different positions in a national well-being strategy. A well-being strategy might imply working towards a better social infrastructure, thus improving welfare provision overall, but it may actually be about foregrounding any one of a number of issues attached to the well-being agenda: social care, mental health resources, more NHS nurses, decarbonisation or increasing the minimum wage.

To understand how well-being data might enable a well-being strategy, we need to side-track briefly into some other historical contexts. We have mainly talked about national indicators: the social indicators' movement as an international imperative to change the way progress was measured (in the 1960s) as a project of redistribution, or the more recent second wave (of the 1990s and 2000s) encouraging individual nations and international bodies to devise more complex indices of objective and subjective well-being. The same kinds of data can be collected to evaluate policy decisions, actions and investments, and there are numerous techniques used in policy evaluation. These were generated to value the non-economic in the audit society, but 'they are too liable to be co-opted, in support of some broader notion of efficiency' (Davies 2014, 193). The following sections explore how we arrived at what has been called 'the cult of the measurable' (Belfiore and Bennett 2007, 137) and what that means for well-being data and what we value. 


\subsection{Audit Culture, Value and Public Management}

[T] he 'fact of audit' reduces anxiety, or more positively, produces comfort. (Power 1994, 307)

One of the effects of developing better measures of well-being and human progress is that we are measuring more things. More than this, we are measuring things for more reasons. Some argue that this is just because we can, or a more cynical description might be to ask whether this is just because some people say we can (whether or not we can being still up for debate in some areas of society). Increasing the ways we measure and what we measure has been diagnosed as 'audit culture' (Strathern 2000) and living in 'the audit society' (Power 1994). This has been linked to the idea of a 'Thatcherite revolution' in UK politics ${ }^{15}$ (named by Power 1994), which refers to UK Prime Minister Margaret Thatcher's reforms of how the public sector is managed, as well as how the public sector manages society.

Again, we must deviate into the task of defining some of these key terms. The public sector is responsible for public services in the UK, from the emergency services and healthcare, education and social care, to housing and refuse collection. It is, therefore, inextricably linked to delivery of social policy in a way that results in public managers having to ensure 'a cost effective and friendly service but with the need to defend the involvement of government in the delivery of such a service' (Halachmi and Bouckaert 1995, 324). This process was called 'new public management' (NPM) (Hood 1991).

\section{Box 2.2 The Characteristics of New Public Management}

NPM and has been summarised as:

1. the adoption of private sector management practices in the public sector;

2. an emphasis on efficiency;

3. a movement away from input controls, rules, and procedures toward output measurement and performance targets;

4. a preference for private ownership, contestable provision, and contracting out of public services; and

5. the devolution of management control with improved reporting and monitoring mechanisms. (Hope 2001, 120) 
The NPM processes are inspired by the ways that commercial firms used financial auditing to demonstrate efficiency, with the idea that these should be applied to the public sector. NPM replaced existing aspects of accountability, such as quality control, with 'auditabilty' (Power 1994, 302-303). Many analysts of NPM (and it has many critics) point out that what is bizarre about NPM is that it does not matter what the audit practices are, as it is the idea of having them which is their most effective property.

In other words, in appearance, it doesn't matter which value system (and here I mean moral and political values, rather than numbers) and which kind of valuation tool you use. For example, you might rank items by order of importance or working out the ratio of their value in comparison to other items. It also doesn't matter whether you are deciding the social value of, say, someone choosing books over cigarettes (as George Orwell did), or saving local libraries open versus building new 'superlibraries' as 'palazzos of human thought', ${ }^{16}$ the point is that the technique was used, and so the policy decision can be justified.

Data which enable auditing, therefore, appear to reassure that things are being done correctly, but 'the audit society is the anxious society', according to Power $(1994,307)$. Power argues that the system is set up so that the only way to deal with this anxiety is in the further commissioning of more auditing. Audit for audit's sake does not improve things, but 'audit success or failure is never a public fact' and the 'criteria of success are withdrawn from public discourse' (Power 1994, 308). Think of the recent rise in well-being at work surveys that you may have seen discussed on social media or which sit unanswered in our inboxes. At the time of writing this book, there was not much discussion of how the data these surveys generated had done anything to improve well-being, yet there was much discussion on Twitter (in my bubble, at least) of how they exacerbate ill-being. They can make us feel watched and give us additional administrative tasks in the service of an employer who is compelled to audit well-being.

Consequently, the logic of NPM and its use of data to audit how policy decisions have performed (or how successful they were at achieving their aims efficiently) has trickled into all kinds of management and sizes of company. As we have recently seen, it has also trickled into apps and watches that help us manage ourselves and our own efficiency (which we discuss in greater detail in Chap. 5). The processes of 'audit culture' were initially argued to make policy-making more transparent to 'the public', but how data are used to make decisions, or monitor the effectiveness of such decisions, is not made clear. Arguably, this has resulted in the mechanisms of policy - and the accountability of politicians, civil servants and their decisions-becoming even more obscure to the general public. 
We should remember the point that the first wave of well-being came to an end-in part-as a result of the mistrust of experts in the economic crash of the 1970s (Bache 2012). What is interesting is that the audit culture approach to efficiency which followed this crash has become naturalised as the way that policy is done. It has also become the way our working lives are managed; some of us even audit our efficiency by way of how many steps we walk a day or how many hours we sleep. In audit culture, well-being metrics replace, reinforce and underwrite expertise. We are therefore trusting metrics more than experts, rather than distrusting experts and their metrics, as was the case in the 1970s.

\section{Social Policy}

Just as policy decisions became less fathomable to people, NPM also changed the relationship between people and policy in other ways. Members of the public were increasingly regarded as customers, and compulsory competitive tendering (CCT) was introduced. CCT requires local council services to be tendered out, and the winning contract going to the most 'efficient' tender. The political relevance of this Thatcherite evolution lies in the fact that this government aimed to reduce 'dependency' on the state and encourage citizens to take responsibility for their own welfare.

A social policy-specific example might be the Right to Buy Scheme in the UK. This saw national government encourage local councils to offer up its social housing 'stock' (housing it was responsible for) to buy, for those people living in it. On face value, a policy that enabled more people to own their own home seemed a good one. Over time, people moved from the houses they had bought; consequently, housing that was looked after by the local council became private housing. However, many, many people cannot afford to buy, even rent this new private housing stock. Therefore, the welfare state has to step in to support this new rental market with private landlords and inflated rents for people to rent houses that may have belonged to the public sector 30 years ago, and which are now often left in unhealthy disrepair by private landlords.

In this instance, objective well-being indicators of home ownership, rental prices or homelessness enable researchers, journalists and policymakers to piece together a retrospectively objective view of whether this policy was efficient and good for people's quality of life. In short, it was great for some people, but not for more people over time, and contributes to inequalities (Murie 2015). As we will continue to see, just because measuring well-being claims to improve how we monitor progress, and these 
ideas were born from belief in both redistribution and efficiency, does not mean they will improve welfare or are even value for money. In fact, the issue of value is - in and of itself-also complex and contradictory.

\section{So, What Is Value?}

To complicate the issue further, 'value' not only refers to what counts (what is valuable, or of value), but how to count. It can also be used to describe our values - as the moral codes we live by in terms of what is right and wrong. In this sense the word and meanings of value are incredibly important when thinking about well-being data, especially what it might mean for social and cultural policy.

To assess the value (or worth) of something, people can go about their own personal estimation, perhaps on a scale, for example: 'in a fire I would save my family photos over my TV'. This is a hypothetical ranking system, where you state you value photos more than television. Or people can use (or invent) a measuring device: a tool, which might include systems of rankings or ratings, for example. Crucially, no matter how neutral and scientific these tools and devices are (or claim to be), they perform an act of calculation that assigns value on behalf of the person who invented or is applying the scale (Espeland and Sauder 2007). As Sociologist Bev Skeggs explains, 'values will always haunt value' (Skeggs 2014, 1). Metrificationas the process of converting aspects of life into metrics for measurementdoes represent existing inequalities, so that they can be addressed. However, it can also reproduce inequalities set out by demographics, such as class and race. This is a broader and bigger argument that we will return to, but let me begin to explain with the example of the photographs versus the TV.

What's interesting about the idea that you would save old family photos over your television is that this is an expression of your values, as a sort of moral value - or the kind of person you see yourself as - as much as it is scale of values (that you could translate into numbers). So, like any rankings scale, or well-being index, they express the values of the person who designed them. Sometimes a well-being index that is a ranking system might want to appear as if it cares about one thing, when in fact it cares about something else entirely. This is also true of people, and when you ask them about themselves, they may feel like they might be being judged in some way (asking people questions can have that effect, see Chap. 9). For example, many people may want to look like the sort of person who would save photos of their family, rather than a surround sound TV, because they think that will make them appear a better person. Sociologists have long been interested in the way we judge our own actions and compare them to the actions of others. 
Sociologists often call this a process of 'distinction', after Pierre Bourdieu (1984). Bourdieu has proved very influential in how people understand class (working class, middle class, etc.). This includes how we classify and categorise each other in day-to-day life, as well as how society is ordered unequally. This means-as Skeggs (afore-cited) tells us-judgements about how we classify ourselves and each other affect how we also come to value things. ${ }^{17}$ This is also wrapped up in how we want our 'taste' to be understood by others - what we like and dislike, or what we think is good and bad. So, how we want to express our taste, through music, for example, relates to other people's perceptions, values and how we wish to be seen by them. Likewise, taste can indicate social position or privilege. People judge people's class based on the beer they drink, the clothes they wear and what they say they watch on TV. It is a cultural cliché to joke that 'the middle classes just don't understand the importance of a giant telly' (Moran 2019), but that also they pretend they don't watch telly at all. This trope is an attempt to understand how a group of people value things in relation to their values.

Taste: how it is expressed and how we show our taste are very much embedded in cultural life, helping people to feel equal to their peers, or demonstrate superiority over others. For example, you might say, 'Lauren has a good taste in music', but what you decide is 'good' is different from what I decide is good. It is all caught up in this process of distinction, of how we classify people, and this is influenced by class. It also allows people to undermine perceived norms (what the majority does). For example, people in UK sub-cultures (whether rave, punk or Grime) might like similar things, products and clothing that are deliberately distasteful to many. How people 'use' this to navigate or succeed in social groups is called cultural capital (Bourdieu 1984; Bennett et al. 2009). Cultural capital means that how people connect to particular culture (e.g. knowledge of music, food, travel and history) can give them a particular privilege, but that the more privilege you have to start, the easier it is to gain. Evidence suggests that people's cultural capital changes how they value things and what they say are valuable.

So, how people answer a question on how they value one thing over another might change from a socially controlled situation (such as answering a questionnaire or social survey) to a real-life situation for many reasons and what people value differs quite a lot. In fact, in any mundane moment, any subjective valuing system might appear. Someone may wish to disguise the fact that they actually value the financial worth of their TV more than the priceless photographs, because this may be seen as crass or shallow. They might use another value system, for example: 'well, I would 
spend more time in the future watching TV than I would spend looking at photographs, therefore the TV would bring me more joy' (were they to use the Marie Kondo ${ }^{18}$ value system of which objects to keep). We might argue they are protecting their future well-being here? Or they might think, what would I pay to replace these items? These are all examples where a rational value is applied to one object over another using a ranking system where the value of one thing is based on its relationship to another.

In cultural policy terms, the TV and the photo album might be considered relative: they could be categorised as cultural objects. For the UK's 'Happiness Tsar', Lord Layard, these two items could symbolise two aspects of culture he has pitted against each other: watching television is responsible for depreciating well-being in the country of Bhutan, because it reduced family relations (see Layard 2006, 77-78; and further discussion in Oman 2020 and Chap. 6). Couched in these terms, the TV has a proxy value that is bad for family relations, while the photo album represents a positive, symbolic value of the family; thus, one is good for well-being and one is bad.

The photo album and the TV could also be seen as incommensurable, meaning that they do not share enough in common to enable comparison. For example, the photos may have emotional value and are unlikely to hold much economic value (for most families, at least); the TV, perhaps, the other way around. But who is to assume that someone's TV isn't a family heirloom, when their photo album may be one where those that houses all the photos which have been rejected because they were badly taken? So we assume and judge how people value things over other things as making them a better person when we don't know about them: their rationales of value, or

\section{Box 2.3 Intrinsic and Extrinsic Value}

Extrinsic Value is value from external factors.

- Also known as Utilitarian Value.

- Placing a value on something, say, a park, based on what we can get out of it or get from it.

Intrinsic Value is something's own inherent qualities.

- Can be moral, ethical, emotional or spiritual value.

- Do animal species have value even if we can't 'use' them? 
whether an object holds intrinsic or extrinsic value for them. Indeed, we are in no position to decide what should be valuable to them and why.

The problem with categories and ranking systems is that they have to assume all TVs are the same and all photographs are the same on at least one dimension. Also, how we judge people's behaviour using these categories is based on assumptions which are organised by class and race and disability, by gender and place and time; the tendency to judge people for watching TV is very classed, for example, and may not consider how able-bodied they may be, or indeed the quality of their relationships with people who may be in a family album. Value systems and tools also, therefore, tend to generalise who people are in order to make them 'commensurate' which is a process of making different things understandable in relation to each other.

\section{Economics, Value and Human Behaviours}

As observed by the historians of the hedonimeter (Colander 2007), economics has trends: periods of time where ideas, approaches and aspirations for what should be possible ebb and flow. This is not unlike any discipline or, to be honest, act of human effort. Following Edgeworth's failed dreams of a hedonimeter in the nineteenth century, economics largely lost interest in understanding the motives behind human behaviour in this way.

Instead of wanting to know how people felt about something, it was deemed sufficient to observe behaviour through consumption as a proxy for feeling. When someone buys a widescreen TV, a photo album, a frozen pizza or an avocado, the implicit assumption is that they make this purchase because it offers them satisfaction or makes them happy somehow. This presumes that people's preferences are revealed in such choices. In fact, it was thought that everything outside of the observable was beyond the realm of economists' study (i.e. Scitovsky 1976).

So, understandably, people tend to think of economics as being about the economy, but the discipline is far more than that. Some popular economists call economics 'the logic of life' (Harford 2008) while others dispute the 'hype' and 'megalomania' of some popular economists (Chang 2014,19 ). Crucially, economics aims to understand the value of things to different people, and how much of any resource is estimated to be needed for particular populations in different domains (aspects) of their lives. Therefore, the discipline of economics is used for insights into how investment or resources should be distributed across a population. Or, to make the policy decision between, say, saving older, smaller community libraries, or investing in new 'super-libraries'. 


\section{Box 2.4 Positive and Normative Economics}

It can be helpful to know the difference between positive and normative economics.

Positive economics attempts to explain what is happening or what has happened thus far. This might include the relationship between investment in super-libraries and how that has changed library usage. Although other changing societal factors will affect how you can measure this over time. For example, confounders will include digitisation, the rise of the audio book and of course the market forces of Amazon. A confounder confounds (or confuses) the possibilities of measuring a direct relationship, as such, economists try and 'control for' these effects. We shall get to this later with examples in Chaps. 7 and 8.

Normative economics aims to evaluate what should happen. This branch of economics draws heavily on philosophical or theoretical arguments to think about what is 'fair' and 'just'. It is, therefore, based on value judgements. This means that the policy decision to direct limited resources towards saving older, smaller community libraries because of the social benefits in local communities are weighed up against building new, super-libraries, for example, which update technology and perhaps encourage different groups to use them.

Both positive and normative economics have roles in evaluating the kinds of policy interventions described in audit culture and throughout the book. Economics forms the foundations of what is called the HM Treasury Green Book in the UK-and of how most OECD member countries evaluate their policy decisions. While the flaws of 'audit culture' have been presented briefly above, it is also important that evaluation of policy decisions happens: that policy-makers are accountable and that resources are handled with care and with a view towards social justice. What is called consequentialist welfarism dictates that actions should be evaluated by their outcomes and that the outcome which matters most is welfare.

Welfare in this instance does not only refer to the welfare state, but 'how people are doing'. So, economists have been trying to find the best ways to evaluate how a policy intervention impacts on how people are doing. Box 2.5 holds four key ideas of valuation that will help understand approaches that will appear throughout the book. 


\section{Box 2.5 Four Key Approaches to Valuation}

Revealed preference was introduced by the American economist Paul Samuelson in 1938. Samuelson decided that consumers' preferences are revealed by what they purchase. The implications of this idea are that we can look at how people purchased one thing over another and assess the circumstances in which these purchases were made. This context may consider other things they may have purchased, how much these things might have cost and the limits people may have in their income.

Even the economists don't all believe that all preferences can be revealed in this way, by proxy. Stated preference techniques involve asking people what they would be willing to pay for something. Or, in public policy terms, sometimes this involves the hypothetical example of asking whether they would be prepared to pay more taxes to reduce hospital waiting times, for example. Because these approaches involve asking people their opinion, they are expensive to administer and, as we now know, there are doubts that what people state or declare is their preference is their actual preference.

Quality Adjusted Life Years (QALYs) is a form of economic evaluation of policy interventions that is particularly useful in health policy decisions. It involves estimating the value of quality and quantity in years of human life remaining for a patient following a particular treatment or intervention. It is often measured on a scale in terms of the person's ability to carry out the activities of daily life, and freedom from pain and mental disturbance. This is then translated into an economic analysis of cost-effectiveness for often very different health interventions. This process makes different things commensurate for easy comparison.

In the last ten years, Well-being Valuation has increasingly appeared across domains of social policy. This takes well-being data, say life satisfaction data, to calculate the impact of something which has no market value, or for which market value is not its primary value, as is common in much of social and cultural policy. There are many years of research on the relationship between income and well-being, and, although this is not fixed, some of the estimates are considered robust. Three data points can be taken from a survey. Let's say access to parks, life satisfaction and income. The Well-being Valuation approach works on the basis that you can not only find the relationship between parks and life satisfaction, but that you can take what you also 'know' about income and life satisfaction to estimate the value of this relationship in economic terms. We shall come back to this step by step in Chap. 9. 


\section{What Is Social Value?}

There is no single authoritative definition of 'social value'. Nevertheless, several leading organisations in this field do provide similar explanations of it. These explanations are almost always within the context of measuring social value. (New Economics Foundation 2016)

The debate around value, its definition and its measurement will never be one on which consensus can easily be reached (if ever), but one which will require on-going negotiations of values, pressures, interests and power. (Belfiore 2015, 107)

One of the earliest uses of the term 'social value' on record dates from 1872, advocating 'the Scientific and Social Value of the British Medical Association' (Shettle 1872). What is particularly interesting in our ongoing discussions in the book is that the term emerged as a compulsion to assert the importance of an organisation that is both an intellectual and a practical endeavour to improve human well-being. Welfare economicsthat is how the government can improve social welfare or well-being, is referred to in the UK Government's guidance on the appraisal and evaluation of policies, projects and programmes (the Green Book) as social value.

While the term 'social value' is widespread, there is little discussion of what it means in practice-and, again, when there is, there is much disagreement (Mulgan 2010; Barman 2016). More recently, the idea of social value has been used to describe the distinctive contributions of commercial companies and third sector organisations, such as charities or community groups, or a domain of society. Social values and value are also expressed via Corporate Social Responsibility, where, as Bill Gates said in the 2008 World Economic Forum, 'more people can make a profit, or gain recognition, doing work that eases the world's inequities' (Gates 2008). Such 'good work' is often incentivised by governments via tax breaks (McGoey 2019). Thus, the value to these companies of 'good work' exceeds the social value, instead being very much about private and corporate value which is, of course, ultimately about wealth generation for those already most wealthy.

In social policy terms, examples could include the social value of housing (HACT 2020; IPPR 2019) or the arts. The latter is touched on in Chap. 6 when we reflect on cultural policy as social policy. In the UK, the Public Services (Social Value) Act 2012 (UK Parliament 2012) builds on some of the principles of NPM described in the last section. It legally 
requires public bodies to consider how the services they commission and procure might improve economic, social and environmental well-being.

The idea of the Social Value Act is that calculating the potential social value created by public and voluntary services helps to ensure value for money. This also acts as an impetus to create additional value. In other words, the aim is for the impact of any public service to exceed the activity or programme being delivered. An example of this can be found in the domain of social housing. The argument for this is that in building new housing that is better quality than that which preceded it, it is not only housing which is improved, but the quality of life of those who live in these houses. It is also argued that this 'regeneration' will improve the quality of life of those people who live near this housing, as it will develop the area in various ways. ${ }^{19}$ Your value-added could be the addition of a public park (where before it was brown land or wasteland, for instance, and thus unusable) and perhaps commission some form of public art with the development.

The Minister for Civil Society announced a review of the act (February 2017), emphasising that a commitment to social value ensures that public sector bodies are able to maximise the benefits of 'tax-payers' money'. This was after the collapse of Carillion, a private company, that specialised in public sector contracts across defence, transport, education and health. Contemporary critics said that 'the preoccupation with costs had hit the quality of public services because the outsourcing companies were sent a clear signal that cost, rather than quality, was the government's consistent priority' (Reuters 2018). The changes were intended to help restore public trust and confidence in outsourcing, by renewing focus on wider social values and increasing transparency (Reuters 2018). In other words, NPM and auditing had resulted in large private companies that not only delivered poor public services, but which went bust because 'efficient' meant cheap, thus costing more than was saved.

There is increasing evidence that the preoccupation with social value results in promises that are not kept. One example is with the promises of affordable housing in regeneration projects. These emerge from a commitment to contribute to social justice and well-being by improving infrastructure and retaining aspects of welfare redistribution. In other words, rather than just building more luxury flats for more 'lucky' and privileged people to move into, and the 'value' of the project going to the developers through economic rewards, the rationale is that affordable housing enables key workers to live in the centre of cities with housing issues, such as 
Manchester and London. As part of audit culture, councils have targets to address the housing shortage in such cities, but the economic value of the homes built are at odds with, and arguably get in the way of, the social value of new houses for people who need them. This state of affairs can be dangerous and at its very worst, cost the lives of many, as in the Grenfell tragedy, 4 June $2017 .^{20}$

Therefore, when we talk of social value, well-being metrics and efficiency, it is vital to ask: whose value is added when we mean 'social' value? We might also ask, who is the social of social policy? Who does it benefit?

\subsection{Conclusion: Well-Being as a Tool of Policy}

There are rising numbers of well-being metrics, which are increasingly used by those who want to know more about people and populations. These data influence national policies and international initiatives. The use of well-being data to make policy decisions is said to be premised on Jeremy Bentham's Greatest Happiness principle: that 'the right moral action is the one that produces the greatest happiness', and therefore, 'the best public policy is the one that produces the greatest happiness' ${ }^{21}$ As the introduction outlines, for some years there have been hopes to understand the well-being of a population at any given moment, which can then be traced over time. New models have been developed with the aspiration to appraise the impact of particular policy interventions by assessing their impact on specific measures of well-being.

An evaluation of how a particular action has impacted on the well-being of people or populations allows for predictions as to how similar choices will impact in the future. We may not know what will happen, but people in power like to make educated guesses. Governments and other agencies use this information to judge which policies are thought to 'maximise' well-being. According to the rationales of NPM, it is considered possible to estimate the most efficient way of increasing well-being by making decisions using econometric models and subjective well-being data to estimate impact valuations.

The supposedly neutral frameworks and technologies used to decide which lives benefit, and which do not, are, of course, never truly impartial (Williamson 2015; Oman 2015). Choices are made at all junctures when evaluating a policy action, and in the 'science' which informs the evidence: what is measured: what is included and excluded from the models and what proxies will be used. In times of increasing inequality, improving the well-being of the majority, a little bit, is potentially all the more dangerous 
for those with the least well-being, especially as it is 'easier to improve the quality of life of people who have relatively high levels of well-being to start with' (Oakley et al. 2013). This opens up questions for how knowledge about well-being is used, and in turn, affects well-being?

This naturalised belief that progress is about striving for well-being is engrained in society, becoming a central logic of policy-making and in our everyday lives. Yet, well-being is not a fixed concept; it shifts depending on who is using it when, and in what context. As we have seen, it has different levels of influence and impact and can be dangerous if used neglectfully. As a tool of policy, well-being is a concept that is applied in various ways which can be implicitly or explicitly guided by valuation. These definitions, histories and contexts are important and come to guide our knowledge of, understandings, measurements and policy implementations of well-being. Thus, reviewing how they all work together, as this chapter has done, is a useful exercise in introducing how we know well-being through data. Crucially, this background forms what well-being data are, where well-being data come from and how they are analysed, as we shall discover in the next chapter.

\section{Notes}

1. You may be used to thinking of data as one thing. In this book, we will use data in the plural, as data are made up of many things. This also acknowledges that well-being data or data about well-being are so varied, as we shall discover.

2. For example, the OECD Guidelines on Measuring Subjective $(2013,10)$ say: 'The measurement of subjective well-being is often assumed to be restricted to measuring "happiness". In fact, subjective well-being covers a wider range of concepts than just happiness.'

3. Aristotle's ideas of the good society are not without flaws. In order for Athenians to have the time to engage in the activities of a good society, slaves performed duties that were manual and thought less skilled. They were considered and treated as an underclass. Arguably, these are not the conditions of a 'good society'.

4. Data about well-being have different units of analysis. In other words, some well-being data are analysed about individuals, and some about whole countries. Chapter 3 expands on these differences in more detail.

5. Algorithm still means any form of automated instruction. The majority of algorithms are simpler than most people think and can be a single 'if something is $\mathrm{X}$, then do this' statement. Contemporary algorithms are long sequences of these instructions.

6. Aristotle has even been called 'the father of racism'; Sears 2018. 
7. While this is a nice idea, we know that actions which focus on improving the material living standards of the largest part of population can lead to minorities being extremely unhappy through neglect and maltreatment.

8. Geoff Bowker says that 'raw data is both an oxymoron and a bad idea; to the contrary, data should be cooked with care' (Bowker 2005, 184).

9. The EconLit database is considered the authority on economic research citations and abstracts. It is managed by American Economic Association and contains more than 1.4 million records, indexed from 74 countries, with citations and abstracts dating back to 1886 .

10. Similar to contemporary inequality arguments, such as Piketty 2013.

11. The Commission on the Measurement of Economic Performance and Social Progress (CMEPSP) is also referred to as the Stiglitz-Sen-Fitoussi Commission after the surnames of those who led it. It was a commission of inquiry created by the French Government in 2008 and so is also referred to by the name of Sarkozy, as France's president.

12. The ONS began measuring personal well-being in April 2011 to provide the indicator that the ONS call 'Personal Wellbeing' (see e.g. ONS 2015 for more detail).

13. The term was in fact coined by Brickman and Campbell in 1971.

14. See, for example, the What Works for Wellbeing website (2016) on addressing well-being inequalities.

15. Although this change in management of the public sector was also seen in the US, Australia and other countries (Hood 1991).

16. In the early $2010 \mathrm{~s}$, there was a wave of building 'super-libraries' in poorer communities, such as Peckham and Canada Water, as well as major city libraries elsewhere. Birmingham city council's leader, Mike Whitby, said of its $£ 193$ million Library of Birmingham, 'It will be much more than just a library. Perhaps we should call it a palazzo of human thought', cited in Jeffries (2010).

17. There is much work which addresses these issues of class, geopolitics and stigma, that there is no room to repeat here. Key texts include Skeggs and Loveday (2012); Bennett et al. (2009). See also Tyler and Slater's 2018 special issue of The Sociological Review.

18. Marie Kondo, a Netflix sensation, has encouraged people to go through their belongings to de-clutter by way of a value system that asks people to anticipate future joy.

19. 'Regeneration' may seem a good well-being solution. However, resulting 'gentrification' means that poorer and more vulnerable residents are pushed off social housing estates, and priced out of their local communities. A high-profile example of this is London's Heygate estate which was demolished and replaced by luxury flats, rather than replacement social housing. As the rental value of the area increased through gentrification, 
the rental values of surrounding areas are further inflated. Therefore, the displaced residents have to move far from the community in which they had been living and the housing and social conditions to which they move are sometimes worse; hence their life chances and well-being are diminished, not enhanced.

20. Notably, the dangerous cladding which accelerated the fire remains on many buildings some years later (Kennedy 2019).

21. This description of 'the Greatest Happiness principle' is taken from Layard's introduction to Bentham, in his book, Happiness: Lessons from the New Science $(2006,5)$. Although a footnote later in the book points to the fact that Bentham corrected this phrase later, saying that he meant the greatest total sum of happiness $(2006,262)$. This is further discussed in Chap. 4 in the section on the Greatest Happiness principle.

\section{REFERENCES}

ACE. 2018. Arts and Culture in Health and Wellbeing and in the Criminal Justice System: A Summary of Evidence. Arts Council England. https://www.artscouncil.org.uk/publication/arts-and-culture-health-and-wellbeing-and-criminaljustice-system-summary-evidence.

Allin, P. 2007. Measuring Societal Wellbeing. Economic \& Labour Market Review l (10): 46-52. https://doi.org/10.1057/palgrave.elmr.1410157.

Aristotle. 1976. The Ethics of Aristotle: The Nicomachean Ethics. New York: Penguin Classics.

Bache, I. 2012. Measuring Quality of Life for Public Policy: An Idea Whose Time Has Come? Agenda-Setting Dynamics in the European Union. Journal of European Public Policy 20 (1): 21-38. https://doi.org/10.1080/1350176 3.2012.699658.

Bache, I., and L. Reardon. 2013. An Idea Whose Time Has Come? Explaining the Rise of Well-Being in British Politics. Political Studies 61 (4): 898-914. https://doi.org/10.1111/1467-9248.12001.

Barman, E. 2016. Caring Capitalism: The Meaning and Measure of Social Value, 266. New York: Cambridge University Press.

Beer, D. 2016. Metric Power. London: Palgrave Macmillan.

Belfiore, E. 2015. "Impact", "Value" And "Bad Economics": Making Sense of the Problem of Value in the Arts and Humanities. Arts and Humanities in Higher Education 14 (1): 95-110. https://doi.org/10.1177/1474022214531503.

Belfiore, E., and O. Bennett. 2007. Rethinking the Social Impacts of the Arts. International Journal of Cultural Policy 13 (2): 135-151. https://doi. org/10.1080/10286630701342741.

Bennett, T., et al. 2009. Culture, Class, Distinction. London: Routledge.

Bentham, J. 1996 [1789]. An Introduction to the Principles of Morals and Legislation. Oxford: Clarendon Press. 
Berry, C. 2014. Wellbeing in Four Policy Areas: Report by the All-Party Parliamentary Group on Wellbeing Economics. London: New Economics Foundation.

Bourdieu, P. 1984. Distinction: A Social Critique of the Judgment of Taste. Cambridge, MA: Harvard University Press.

Bowker, G.C. 2005. Memory Practices in the Sciences. Ed. G.C. Bowker. Cambridge, MA: MIT Press.

Brickman, P., and D.T. Campbell. 1971. Hedonic Relativism and Planning the Good Society. In Adaptation Level Theory: A Symposium, ed. M.H. Appley, 287-302. New York: Academic Press.

Bruni, L., and P.L. Porta. 2005. Introduction. In Economics and Happiness: Framing the Analysis, 1-28. Oxford: Oxford University Press.

Cameron, D. 2010. Prime Minister's Speech on Wellbeing. Cabinet Office, Prime Minister's Office. https://www.gov.uk/government/speeches/pm-speechon-wellbeing.

Cederström, C., and A. Spicer. 2014. The Wellness Syndrome. Cambridge: Polity Press.

Chang, H.-J. 2014. Economics: The User's Guide. London: Pelican.

Colander, D. 2007. Retrospectives: Edgeworth's Hedonimeter and the Quest to Measure Utility. Journal of Economic Perspectives 21 (2): 215-226. https:// doi.org/10.1257/jep.21.2.215.

Croly, H. D. 1962. 'About rethinking the system of national accounting', The New Republic, vol. 147, p. 29.

Davies, W. 2014. The Limits of Neoliberalism: Authority, Sovereignty and the Logic of Competition. London: SAGE. https://sk.sagepub.com/books/the-limitsof-neoliberalism. Accessed 31 March 2021.

- 2015. The Happiness Industry: How the Government and Big Business Sold Us Well-Being. London: Verso.

Dodge, R., et al. 2012. The Challenge of Defining Wellbeing. International Journal of Wellbeing, 2 (3). https://www.internationaljournalofwellbeing.org/ index.php/ijow/article/view/89. Accessed 30 March 2021.

Dolan, P. 2014. Happiness by Design: Finding Pleasure and Purpose in Everyday Life. London: Penguin Books.

Doria, L. 2013. Calculating the Human: Universal Calculability in the Age of Quality Assurance. Basingstoke: Palgrave Macmillan.

Easterlin, R. 1973. Does Money Buy Happiness? The Public Interest 30 (3): 3-10. Espeland, W.N., and M. Sauder. 2007. Rankings and Reactivity: How Public Measures Recreate Social Worlds. American Journal of Sociology 113 (1): 1-40. https://doi.org/10.1086/517897.

Fleche, S., C. Smith, and P. Sorsa. 2012. Exploring Determinants of Subjective Wellbeing in OECD Countries: Evidence from the World Value Survey. No. 921. Paris: Organisation for Economic Cooperation and Development. 
Gates, B. 2008. 2008 World Economic Forum - Bill \& Melinda Gates Foundation. Bill \& Melinda Gates Foundation. https://www.gatesfoundation.org/ideas/ speeches $/ 2008 / 01 /$ bill-gates-2008-world-economic-forum. Accessed 28 April 2021.

HACT. 2020. The UK Social Value in Housing Taskforce. HACT. Ideas and Innovation in Housing. https://www.hact.org.uk/news/uk-social-valuehousing-taskforce. Accessed 30 March 2021.

Halachmi, A., and G. Bouckaert. 1995. Re-engineering in the Public Sector. International Review of Administrative Sciences 61 (3): 323-327. https://doi. org/10.1177/002085239506100301.

Harford, T. 2008. The Logic of Life: The Rational Economics of an Irrational World. Random House.

Helliwell, J., L. Richard, and J. Sachs. 2015. World Happiness Report 2015. New York: UN Sustainable Development Solutions Network.

Hood, C. 1991. A Public Management for All Seasons? Public Administration 69 (1): 3-19. https://doi.org/10.1111/j.1467-9299.1991.tb00779.x.

Hope, K.R. 2001. The New Public Management: Context and Practice in Africa. International Public Management Journal 4 (2): 119-134.

IPPR. 2019. Valuing More Than Money: Social Value and the Housing Sector. https://www.ippr.org/research/publications/valuing-more-than-money

Jeffries, S. 2010. The Battle of Britain's Libraries. The Guardian. https://www. theguardian.com/books/2010/mar/07/future-british-libraries-margarethodge

John, N. 2020. Coronavirus Lockdown: Why Sajjan Jindal Fears 'Awakening' Economy Will Be a Challenge. Business Today. https://www.businesstoday.in/ current/economy-politics/coronavirus-lockdown-why-sajjan-jindal-fearsawakening-economy-challenge/story/402231.html

Kaszynska, P. 2021. Cultural Value as Practice: Seeing Future Directions, Looking Back at AHRC Cultural Value Project. In Exploring Cultural Value: Contemporary Issues for Theory and Practice, ed. K. Lehman, I. Fillis, and M. Wickham. Bingley: Emerald Publishing Limited.

Kennedy, S. 2019. Two Years After Grenfell, Why Are Thousands Still Not Safe in Their Homes? The Guardian. https://www.theguardian.com/commentisfree/2019/jun/13/two-years-grenfell-government-blocks-cladding

Layard, R. 2006. Happiness: Lessons from a New Science. London: Penguin.

McGoey, L. 2019. The Unknowers: How Strategic Ignorance Rules the World. London: Zed Books Ltd.

McMahon, D.M. 2006. Happiness: A History. New York: Grove Press.

Moran, C. 2019. Caitlin Moran: The Politics of Mega TVs. The Times. https:// www.thetimes.co.uk/article/caitlin-moran-the-politics-of-mega-tvsdpbr0vt2c. Accessed 30 March 2021. 
Morris, S. 2020. Mindfulness Apps Are Booming in Lockdown-How to Stay Chilled Using Your Phone or on Your Own. The Independent. https://inews.co.uk/ inews-lifestyle/wellbeing/mindfulness-apps-coronavirus-lockdown-explainedchilled-headspace-448667

Mulgan, G. 2010. Measuring Social Value. SSIR. https://ssir.org/articles/entry/ measuring_social_value

Murie, A. 2015. The Right to Buy: History and Prospect. History \& Policy. http://www.historyandpolicy.org/policy-papers/papers/the-right-to-buy-historyand-prospect.

New Economics Foundation. 2016. Social Return on Investment. New Economics Foundation. https://neweconomics.org/issues/entry/socialreturn-on-investment. Accessed 12 January 2016.

Noll, H. 2002. Social Indicators and Quality of Life Research: Background, Achievements and Current Trends. In Advances in Sociological Knowledge Over Half a Century, ed. N. Genov, 151-181. Paris: International Social Science Council.

O'Donnell, G., et al. 2014. Wellbeing and Policy. London: Legatum Institute.

Oakley, K., D. O'Brien, and D. Lee. 2013. Happy Now? Well-being and Cultural Policy. Philosophy and Public Policy Quarterly 31 (2): 18-26. https://doi. org/10.13021/G8pppq.312013.131.

OECD. 2007. Beyond GDP: Measuring Progress, True Wealth, and the Well-being of Nations. OECD. https://www.oecd.org/site/worldforum06/ 38433373.pdf.

- 2013. How's Life? 2013 Measuring Well-being. OECD (OECD Better Life Initiative). http://www.oecd.org/sdd/301307le.pdf.

Oman, S. 2015. Measuring National Well-being: What Matters to You? What Matters to Whom? In White, S. and Blackmore, C. (eds) Cultures of Wellbeing: Method, Place, Policy. London: Palgrave MacMillan.

Oman, S. 2020. Leisure Pursuits: Uncovering the "Selective Tradition" in Culture and Well-being Evidence for Policy. Leisure Studies 39 (1): 11-25. https://doi. org/10.1080/02614367.2019.1607536.

ONS. 1970. Social Trends. Office for National Statistics. https://data.gov.uk/ dataset/f3ba77f8-d598-4db2-a3bc-b59a1578d410/social-trends. Accessed 28 April 2021.

- 2015. Measuring National Wellbeing: Personal Well-being in the UK, 2014 to 2015. Newport: Office for National Statistics.

Perlman, M., and M. Marietta. 2005. The Politics of Social Accounting: Public Goals and the Evolution of the National Accounts in Germany, the United Kingdom and the United States. Review of Political Economy 17 (2): 211-230. https://doi.org/10.1080/09538250500067262.

Piketty, T. 2013. Le Capital au XXIe siècle. Éditions du Seuil: Belknap Press.

Power, M. 1994. The Audit Society. In Accounting as Social and Institutional Practice, ed. A. Hopwood and P. Miller, 299-316. Cambridge: Cambridge University Press. 
Reuters. 2018. Carillion Collapse Exposed Flaws in UK Government Policy: Lawmakers. Reuters. https://www.reuters.com/article/us-carillion-collapseidUSKBN1JZ1H7. Accessed 30 March 2021.

Schoch, R. 2007. The Secrets of Happiness: Three Thousand Years of Searching for the Good Life. London: Profile Books.

Scitovsky, T. 1976. The Joyless Economy: An Inquiry into Human Satisfaction and Consumer Dissatisfaction. Oxford: Oxford University Press.

Scott, K. 2012. Measuring Wellbeing: Towards Sustainability? London: Routledge. https://www.taylorfrancis.com/https://www.taylorfrancis.com/ books/mono/10.4324/9780203113622/measuring-wellbeing-towardssustainability-karen-scott.

Sears, M. 2018. Aristotle, Father of Scientific Racism. The Washington Post. https://www.washingtonpost.com/news / made-by-history / $\mathrm{wp} / 2018 / 04 / 06 /$ aristotle-father-of-scientific-racism/

Seligman, M.E.P., and M. Csikszentmihalyi. 2000. Positive Psychology: An Introduction. American Psychologist 55 (1): 5-14. https://doi.org/10.103 7/0003-066X.55.1.5.

Sen, A. 1999. Commodities and Capabilities. 2nd ed. Delhi and New York: Oxford University Press.

Shettle, R.C. 1872. An Address on the Scientific and Social Value of the British Medical Association. British Medical Journal 2 (625): 677-679.

Sinclair, J. 1798. Statistical Accounts of Scotland. https://stataccscot.edina.ac.uk/ static/statacc/dist/home. Accessed 15 June 2015.

Skeggs, B. 2014. Values Beyond Value? Is Anything Beyond the Logic of Capital? The British Journal of Sociology 65 (1): 1-20. https://doi.org/10.1111/ 1468-4446.12072.

Skeggs, B., and V. Loveday. 2012. Struggles for Value: Value Practices, Injustice, Judgment, Affect and the Idea of Class. The British Journal of Sociology 63 (3): 472-490. https://doi.org/10.1111/j.1468-4446.2012.01420.x.

Strathern, M. 2000. Audit Cultures: Anthropological Studies in Accountability, Ethics and the Academy. London: Routledge.

The Swedish Institute for Social Research. 1968. The Swedish Level-of-Living Survey (LNU). The Swedish Institute for Social Research. https://www.sofi. su.se/english/2.17851/research/three-research-units/lnu-level-of-living/ the-swedish-level-of-living-survey-lnu-1.65112. Accessed 28 April 2021.

Tyler, I., and T. Slater. 2018. Rethinking the Sociology of Stigma. The Sociological Review 66 (4): 721-743. https://doi.org/10.1177/0038026118777425.

UK Parliament. 2012. Public Services (Social Value) Act 2012. London: The Parliamentary Book Shop. https://www.gov.uk/government/publications/social-value-act-information-and-resources / social-value-act-information-and-resources. 
2018. Arts: Impact of Brexit. Thursday 11 October 2018, Hansard, UK Parliament, House of Lords Hansard. https://hansard.parliament.uk/Lords/2018-10-11/debates/64E52F7DD698-40DD-8All-9F50F94E542C/ArtsImpactOfBrexit. Accessed 30 March 2021.

Veenhoven, R. 1984. Conditions of Happiness. Boston and Lancaster: D Reidel Publishing Company.

Vidal, J. 2006. The 7,000 km Journey that Links Amazon Destruction to Fast Food. The Guardian. https://www.theguardian.com/business/2006/ apr/06/brazil.food

What Works for Wellbeing. 2016. What Wellbeing Inequalities Tell Us About the EU Referendum Result. What Works Wellbeing. https://whatworkswellbeing. $\mathrm{org} / \mathrm{b} \log /$ what-wellbeing-inequalities-tell-us-about-the-eu-referendumresult/. Accessed 30 March 2021.

White, M.D. 2014. The Illusion of Well-Being: Economic Policymaking Based on Respect and Responsiveness. Palgrave Macmillan.

Williamson, B. 2015. Testing Governance: The Laboratory Lives and Methods of Policy Innovation Labs. University of Stirling. https://dspace.stir.ac.uk/bitstream/1893/22500/1/WilliamsonB_Testing\%20governance_2015.pdf. Accessed 28 April 2021.

Wolf, M. 2019. The Case for Making Wellbeing the Goal of Public Policy. Financial Times. https://www.ft.com/content/d4bb3e42-823b-1 le9-9935ad75bb96c 849

Open Access This chapter is licensed under the terms of the Creative Commons Attribution 4.0 International License (http://creativecommons.org/licenses/ by $/ 4.0 /$ ), which permits use, sharing, adaptation, distribution and reproduction in any medium or format, as long as you give appropriate credit to the original author(s) and the source, provide a link to the Creative Commons licence and indicate if changes were made.

The images or other third party material in this chapter are included in the chapter's Creative Commons licence, unless indicated otherwise in a credit line to the material. If material is not included in the chapter's Creative Commons licence and your intended use is not permitted by statutory regulation or exceeds the permitted use, you will need to obtain permission directly from the copyright holder.

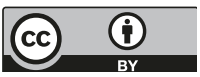

